\title{
Focus Point on Microplastic Pollution: Assessment, Effects and Mitigation Strategies
}

Published online: 8 February 2019 - C) Società Italiana di Fisica / Springer-Verlag GmbH Germany, part of Springer Nature, 2019

The subject of this Focus Point is related to Microplastic pollution, an environmental problem that has received increasing attention in recent years, becoming an emerging research topic. Indeed, even though plastic pollution is a well-known worldwide problem, the discovery of microplastics or even nanoplastics in seas and oceans represents an unexpected change of perspective in the environmental science.

Microplastics are defined as plastic fragments typically smaller than $5 \mathrm{~mm}$, able to partially pass through wastewater treatments plants, accumulating on shorelines and eventually reaching marine ecosystems, where they can remain unaltered for long time, representing a possible risk for marine ecosystems. Due to the complex interactions of microplastics with the environment, the evaluation of their presence, their quantification and the study of their effects on the environment represent a new, very challenging and interdisciplinary topic, which requires different skills from the fields of physical chemistry, environmental science, marine biology, polymer science, physics, and policy and regulation. Actually, as concerns the evaluation of microplastic presence in different environments, there is a strong need to develop and improve physico-chemical methods for their identification, detection, mapping and quantification [1-5]. Studies on the effects of microplastics and of organic contaminants possibly absorbed on their surface on marine organisms are mainly carried out by marine biologists to understand and define the environmental impact of these pollutants [6-8]. Moreover, in the field of polymer science, several efforts are being carried out to understand the degradation kinetics of microplastics in the marine environment and to develop new solutions to mitigate microplastic pollution [9,10]. Finally, policy and regulation aspects cannot be neglected because the relevance of the microplastic pollution requires appropriate regulations and management policies [11].

Starting from this scenario, this Focus Point covers the most relevant aspects related to microplastic pollution, collecting contributions from relevant international authors, who propose new solutions and actions to face this environmental threat.

In more detail, in the first paper, Study on the microplastics release from fishing nets [12], the authors evaluated the release of microfibers from lost fishing nets to the sea by using an interesting approach.

In the second paper, Quantification of microfibres released during washing of synthetic clothes in real conditions and at lab scale [13], the release of microfibers from synthetic clothes during washing was evaluated through two experimental procedures, both in lab and real scale.

In the third contribution, Ubiquitous exposure to microfiber pollution in the air [14], the authors demonstrated the large presence of microplastics in the air in different urban environments, thus suggesting that microplastics can represent a potential threat for human health.

In the fourth paper, Searching and identifying microplastics in marine environment by digital holography [15], the authors proposed a detection method based on digital holography, as a non-invasive technique to search for and reconstruct the shape of different types of microplastics.

Finally, the fifth contribution, Restricting microplastics in the European Union: Process and criteria under $R E A C H$ [16], reported an interesting analysis on the restriction process started by the European Commission regarding intentionally added microplastics, discussing the aspects related to the environmental and health risk assessments as well as the socio-economic analyses and the evaluations of risk management options.

\section{References}

1. La D.K. Kanhai, R. Officer, O. Lyashevska, R.C. Thompson, I. O’Connor, Mar. Pollut. Bull. 115, 307 (2017). 
2. F. De Falco, M.P. Gullo, G. Gentile, E. Di Pace, M. Cocca, L. Gelabert, M. Brouta-Agnés, A. Rovira, R. Escudero, R. Villalba, R. Mossotti, A. Montarsolo, S. Gavignano, C. Tonin, M. Avella, Environ. Pollut. 236, 916 (2018).

3. C.M. Rochman, F. Regan, R.C. Thompson, Anal. Methods 9, 1324 (2017).

4. S.M. Mintenig, I. Int-Veen, M.G.J. Löder, S. Primpke, G. Gerdts, Water Res. 108, 365 (2017).

5. A. Karami, A. Golieskardi, C.K. Choo, V. Larat, T.S. Galloway, B. Salamatinia, Sci. Rep. 7, 46173 (2017).

6. T.S. Galloway, M. Cole, C. Lewis, Nat. Ecol. Evol. 1, 0116 (2017).

7. M. Baini, T. Martellini, A. Cincinelli, T. Campani, R. Minutoli, C. Panti, M.G. Finoia, M.C. Fossi, Anal. Methods 9, 1512 (2017).

8. I. Bernardini, F. Garibaldi, L. Canesi, M.C. Fossi, M. Baini, Mar. Pollut. Bull. 135, 303 (2018).

9. O.S. Ogunola, O.A. Onada, A.E. Falaye, Environ. Sci. Pollut. Res. 25, 9293 (2018).

10. F. De Falco, G. Gentile, R. Avolio, M.E. Errico, E. Di Pace, V. Ambrogi, M. Avella, M. Cocca, Carbohydr. Polym. 198, 175 (2018).

11. D. Xanthos, T.R. Walker, Mar. Pollut. Bull. 118, 17 (2017).

12. A. Montarsolo, R. Mossotti, A. Patrucco, R. Caringella, M. Zoccola, P.D. Pozzo, C. Tonin, Eur. Phys. J. Plus 133, 494 (2018).

13. F. De Falco, G. Gentile, E. Di Pace, M. Avella, M. Cocca, Eur. Phys. J. Plus 133, 257 (2018).

14. A.T. Kaya, M. Yurtsever, S.C. Bayraktar, Eur. Phys. J. Plus 133, 488 (2018).

15. F. Merola, P. Memmolo, V. Bianco, M. Paturzo, M.G. Mazzocchi, P. Ferraro, Eur. Phys. J. Plus 133, 350 (2018).

16. E. Kentin, Eur. Phys. J. Plus 133, 425 (2018).

M. Avella, R. Avolio, M. Cocca, E. Di Pace, M.E. Errico, and G. Gentile 